\title{
Association of Epstein-Barr Virus and Cytomegalovirus Infections with Esophageal Carcinoma
}

\author{
Jamal Sarvari (iD ${ }^{1}$, Ahmad Habibi ${ }^{1}$, Afagh Moattari ${ }^{2}$, Amir Taher Eftehkar Sadat ${ }^{3}$ and Mahin Ahangar \\ Oskouee $\mathbb{1 0}^{4, *}$ \\ ${ }^{1}$ Department of Bacteriology and Virology, School of Medicine, Shiraz University of Medical Sciences, Shiraz, Iran \\ ${ }^{2}$ Gastroenterohepatology Research Center, Shiraz University of Medical Sciences, Shiraz, Iran \\ ${ }^{3}$ Department of Pathology, Tabriz University of Medical Sciences, Tabriz, Iran \\ ${ }^{4}$ Infectious and Tropical Diseases Research Center, Department of Microbiology and Virology, School of Medicine, Tabriz University of Medical Sciences, Tabriz, Iran \\ "Corresponding author: Infectious and Tropical Diseases Research Center, Department of Microbiology and Virology, School of Medicine, Tabriz University of Medical Sciences, \\ Tabriz, Iran. Email: ahangar1342@gmail.com
}

Received 2021 March 13; Revised 2021 September 20; Accepted 2021 September 22.

\begin{abstract}
Background: Given the fact that viral infections play an important role, either directly or indirectly, in around 20 percent of human cancers, this study aimed at investigating the potential association of Epstein-Barr virus (EBV) and cytomegalovirus (CMV) infections in esophageal cancer that is the sixth most common cause of cancer-related deaths.

Methods: In this case-control study, a total of 200 paraffin-embedded biopsies of cancerous and benign esophageal tissues were gathered from the biopsy bank of Imam Reza Hospital, Tabriz, Iran in 2017. All samples were first deparaffinized, and then subjected to commercial DNA extraction. The quality of extracted DNA was evaluated by amplification of the beta globulin gene. Identification of EBV and CMV DNA was performed using primers designed for the EBER region of EBV and the immediate early (IE) region of the CMV genome, respectively.

Results: The mean age of the subjects in the test and control groups was 52.2 (17.1) and 59.9 (18.9), respectively. The distribution of gender (male/female) in patient and control groups was 54/46 and 53/47, respectively. Our results showed that the frequency of $\operatorname{EBV}(\mathrm{P}<0.001)$ and CMV $(\mathrm{P}<0.001)$ in cancerous samples was statistically higher than control group. Moreover, in the cancerous group the rate of EBV was significantly higher in the esophageal adenocarcinomas (EAC) sample (12 out of 70) than esophageal squamous cell carcinomas (ESCC) ( 0 out of 30) $(\mathrm{P}=0.016$ ) but, in the ESCC group, 17 out of 30 subjects were positive for CMV which was significantly higher in comparison with EAC patients (1 out of 70$)(\mathrm{P}<0.001)$.

Conclusions: Findings indicated that EBV and CMV might be contributed to the pathogenesis of EAC and ESCC types of esophageal carcinoma, respectively, although further studies are warranted.
\end{abstract}

Keywords: Epstein-Barr Virus, Cytomegalovirus, Esophageal Carcinoma

\section{Background}

In 2015, 17.5 million patients with cancer and 8.7 million cancer related-deaths have been reported globally. From 2005 to 2015, the number of patients with cancer increased by $33 \%$ (1). Among different cancer types, esophageal carcinoma is the eleventh and sixth most common and life-threatening cancer worldwide, respectively (1). Indeed, around 482578 new esophageal cancer cases and 439000 relevant deaths have been just recorded in 2015, worldwide (1).

There are 2 types of esophageal carcinoma, which include esophageal squamous cell carcinomas (ESCC) and esophageal adenocarcinomas (EAC) based on histological features (2). While the exact etiologies behind these carci- nomas have not yet been further defined, several risk factors are thought to be involved. Indeed, alcohol and mate drinking, smoking, red and processed meat consumption, and human papillomavirus (HPV) infection are reported to be associated with ESCC. Moreover, smoking, body mass index, and red and processed meat consumption appear to be involved in $\operatorname{EAC}(2,3)$.

Viral infections including HPV, Epstein-Barr virus (EBV), hepatitis B and C viruses, human T-lymphotropic virus-1, and polyomaviruses are considered as the major risk factor for about $20 \%$ of all cancers (4-6). Thus, some studies proposed a possible link between viruses such as EBV, HPV, and cytomegalovirus (CMV) with esophageal carcinoma (7-9). 
EBV, as a ubiquitous herpes virus, has a widespread distribution among human populations (10). After primary infection through saliva, it establishes a persistent and lifelong infection in almost all individuals (10). While the direct role of EBV in several malignancies including Burkitt lymphoma, nasopharyngeal carcinoma, and gastric cancer is well documented, its impact on esophageal carcinoma development remains controversial.

The carcinogenesis of EBV is mainly driven by some virus-encoded proteins such as latent membered protein (LMP) 1 and LMP2, which mimic cellular receptors and are engaged in several signaling pathways that induce morphological and phenotypic changes in the epithelial cells. Epstein-Barr nuclear antigens (EBNAs) 1 and 3C have also been implicated in the tumorigenic and metastatic potential of EBV and their role has been evaluated in an orthotropic model of murine breast carcinoma (11). Furthermore, EBV-encoded and EBV-regulated miRNAs appear to play an important role in immune evasion (12). In this regard, EBV Bam-HI A rightward transcripts (BARTs) MicroRNAs target multiple proapoptotic cellular genes result in the promotion of epithelial cell survival (13).

CMV is a member of herpesviridae family and infects a major part of the human population with lifelong persistence (14). CMV replicates in a spectrum of human cells, especially endothelial cells and macrophages, and may produce latency infection (15). Regarding the possible mechanisms involved in CMV carcinogenesis, it has been reported that immediate-early protein (IE) 86 prevents the inhibitory functions of $\mathrm{pRb}$, resulting in the release of E2F and induction of cell cycle (16). Moreover, IE86 and the product of the UL44 gene bind to and inhibit p53, which can prevent apoptosis and increase the mutation rate (17, 18). IE86 may not only function as an immunosuppressive but also as an inducer of angiogenesis, which has an important role in tumor growth and survival $(16,19,20)$. Although CMV may not exert a direct role in tumor development, it triggers tumor progression by cells cycle regulation (20). Thus, CMV may act as an 'oncomodulator' in changing the tumor microenvironment towards the initiation or progression of the tumor (21).

The presence of DNA, RNA, and proteins of CMV was found in several cancer types including prostate, colorectal, breast, glioblastomas, medulloblastoma, mucoepidermoid cancer of the salivary gland, and rhabdomyosarcoma (20). In Iran, the CMV DNA genome has also been detected in several types of cancer including colorectal (22), oral squamous cell carcinoma (23), and gastric cancers (24). Data with regards to the plausible role of HCMV in esophageal cancer development are limited.

\section{Objectives}

This study was conducted to evaluate the plausible association between EBV and CMV infections and esophageal carcinoma in the Tabriz city, northwest Iran.

\section{Methods}

A total of 205 paraffin-embedded biopsies of esophageal specimens including 103 patients with invasive ESCC and EAC as a case group and 102 subjects with benign esophageal tissues as a control group were gathered from biopsy bank of Imam Reza Hospital, Tabriz, East Azerbaijan, Iran. The state of disease and relevant tissue samples had been examined by a specialist pathologist and were selected based on the pathology reports from January 2014 to December 2016. The study was approved by the Ethics Committee of the Shiraz University of Medical Sciences (IR.SUMS.REC.1395.51123) and informed consent was obtained before sample collection.

Ten sections $(10 \mu \mathrm{m})$ of the paraffin-embedded block were cut and undergo de-paraffinization as previously described (5). DNA was extracted using tissue DNA extraction Minikit (Yektatajhiz, Tehran, Iran) according to the manufacturer's instruction. The extracted DNA was stored at $-20^{\circ} \mathrm{C}$ until use. All extracted DNA samples were initially subjected to PCR with the $\beta$-globin gene to confirm the quality of the extracted DNA. Five negative samples were excluded from the study. PCR reaction was performed on qualified samples in a total volume of $25 \mu \mathrm{L}$ by PCR master mix (Yektatajhiz, Tehran, Iran). The characteristics of the primers used for amplifying the human $\beta$-globin gene, the EBER region of EBV, and the immediate-early region of CMV are shown in Table 1(25-27).

In this study, DNA extracted from BC-95 cells and known CMV DNA positive samples (taken from a patient) were used as positive controls for EBV and CMV, respectively. PCR amplification was carried out in a thermocycler using the following cycling programs: For EBV: 1 cycle of $95^{\circ} \mathrm{C}$ for $2 \mathrm{~min} ; 39$ cycles of $94^{\circ} \mathrm{C}$ for $30 \mathrm{sec}, 60^{\circ} \mathrm{C}$ for $1 \mathrm{~min}$, $72^{\circ} \mathrm{C}$ for $2 \mathrm{~min} ; 1 \mathrm{cycle}$ of $72^{\circ} \mathrm{C}$ for $10 \mathrm{~min}$ and for CMV: 1 cycle of $95^{\circ} \mathrm{C}$ for $4 \mathrm{~min} ; 35$ cycles of $94^{\circ} \mathrm{C}$ for $1 \mathrm{~min}, 50^{\circ} \mathrm{C}$ for $1 \mathrm{~min}$, $72^{\circ} \mathrm{C}$ for $1 \mathrm{~min} ; 1$ cycle of $72^{\circ} \mathrm{C}$ for $10 \mathrm{~min}$. All amplified products were visualized on $1.5 \%$ agarose gel and the presence of a 229 and 240 base pair amplicon considered as EBV and CMV DNA, respectively. EBV and CMV positive samples were repeated to double-check the results.

\subsection{Statistical Analysis}

Statistical analysis was carried out using SPSS (Chicago, IL, USA) software version 23 for Microsoft Windows@. The results were statistically analyzed using the chi-square test and $t$-test. P-value $\leq 0.05$ was considered significant. 


\begin{tabular}{l|l|c|c}
\hline Table 1. The Sequences and Other Characteristics of the Primers Used in This Study & \multicolumn{1}{|c}{ Amplicon Size (bp) } & References \\
\hline \multirow{2}{*}{ Region } & \multicolumn{1}{|c|}{ Primer Sequence } & 250 & $(25)$ \\
\hline \multirow{2}{*}{ EBV EBER region } & 5'-AACTTCATCCACGTTCACC-3' & & \\
\cline { 2 - 4 } & 5'-GAAGAGCCAAGGACAGGTAC-3' & \multirow{2}{*}{108} & $(26)$ \\
\hline \multirow{2}{*}{ CMV IE region } & 5'-CCCTAGTGGTTTCGGACACA-3' & & (27) \\
\cline { 2 - 4 } & 5'-ACTTGCAAATGCTCTAGGCG-3' & 240 & \\
\hline
\end{tabular}

Abbreviations: EBER, Epstein-Barr virus-encoded small RNA; IE, immediate early.

\section{Results}

\subsection{Demographic and Pathologic Characteristics}

In the carcinoma group, 70 (70\%) samples were EAC and 30 (30\%) were ESCC type. The mean age (standard deviation; SD) of study subjects in the case and control groups was 52.2 (17.1) and 59.9 (18.9) years, respectively (Table 2). In addition, the mean age of the patients with ESCC and EAC was 51.1 (20.2) and 52.7 (15.8) years, respectively (Table $3)$. The mean age of CMV positive and negative samples in the ESCC group was 55.1(23) and 45.7 (14) years, respectively. Moreover, in the EAC group, the mean age of EBV positive and negative subjects was 50.6 (12) and 53.1(16) years, respectively, which was not significantly different. The gender distribution of the case group was 54 males and 46 females (Table 2). Moreover, the gender frequency of the control groups was 53 males and 47 females (Table 2).

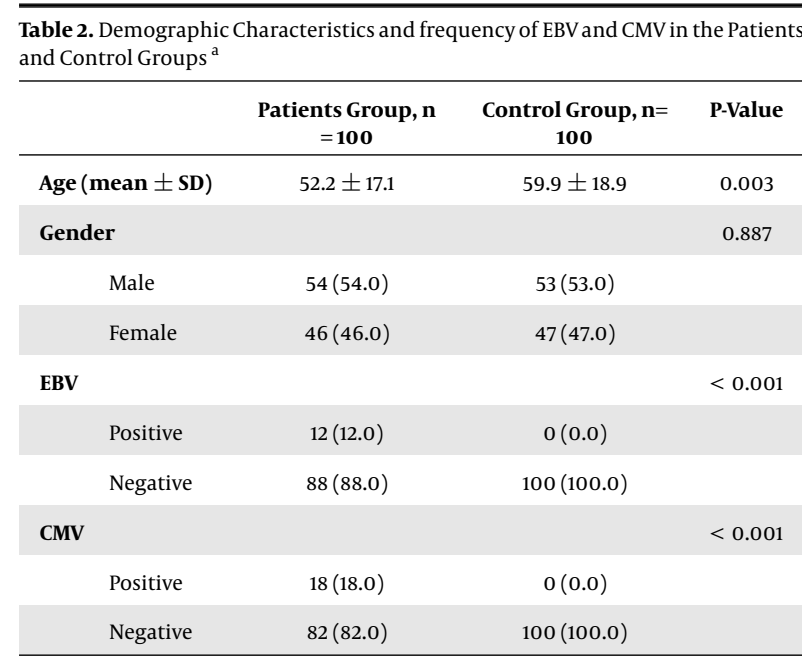

${ }^{\mathrm{a}}$ Values are expressed as No. (\%) unless otherwise indicated.

\subsection{PCR for EBV DNA Genome}

According to the results, 12 out of 100 (12\%) cancerous samples were found to be positive for the EBV genome and
Table 3. Demographic Characteristics and Frequency of EBV and CMV in the Patients (ESCC and EAC) Group ${ }^{\mathrm{a}}$

\begin{tabular}{|c|c|c|c|}
\hline & \multicolumn{2}{|c|}{ Patients Group } & \multirow{2}{*}{ P-Value } \\
\hline & ESCC, $\mathbf{n}=\mathbf{3 0}$ & $\mathrm{EAC}, \mathbf{n}=\mathbf{3 0}$ & \\
\hline Mean age & $51.1 \pm 20.2$ & $52.7 \pm 15.8$ & 0.673 \\
\hline Gender & & & 0.872 \\
\hline Male & 16 & 37 & \\
\hline Female & 14 & 33 & \\
\hline EBV & & & 0.016 \\
\hline Positive & $0(0.0)$ & $12(17.0)$ & \\
\hline Negative & $30(100.0)$ & $58(83.0)$ & \\
\hline CMV & & & $<0.00$ \\
\hline Positive & $17(56.6)$ & $1(1.4)$ & \\
\hline Negative & $30(53.4)$ & $70(98.6)$ & \\
\hline
\end{tabular}

Abbreviations: ESCC, esophageal squamous cell carcinomas; EAC, esophageal adenocarcinomas.

${ }^{a}$ Values are expressed as No. (\%) unless otherwise indicated.

none of the samples in the control group was positive, as shown in Table 2, the difference was statistically significant (P value $<0.001)$. Moreover, the rate of EBV positivity was significantly higher in the EAC group (12 out of 70) when compared to ESCC patients ( 0 out of 30$)(P$ value $=0.016)$ (Table 3).

\subsection{PCR for CMV DNA Genome}

While 18 out of 100 (18\%) cancerous samples were found to be positive for the presence of CMV genome, none of the benign control group were positive and the difference was statistically significant (P value $<0.001$ ) (Table 2 ). The rate of CMV positivity was also significantly higher in the ESCC group (17 out of 30 ) than EAC patients (1 out of 70) (P value $<0.001$ )(Table 3 ). 


\section{Discussion}

There is compelling evidence that supports a direct and crucial role of EBV infection in developing several malignancies including Burkitt lymphoma, nasopharyngeal carcinoma, gastric cancer, B-cell non-Hodgkin's, and Hodgkin's lymphoma, however, the potential role of EBV infection in esophageal carcinoma remains controversial $(10,28)$.

In the present study, EBV positivity was significantly higher in cancerous tissues compared to benign tissues. In addition, the rate of EBV positivity was significantly higher in patients with EAC than those with ESCC. Regarding the higher frequency of EBV in cancerous tissues, Wang et al. detected EBV DNA in 11 (35.5\%) cases with esophageal cancer (29). Furthermore, Zhang et al. reported the association of EBV and esophageal cancer by showing that 21 (30\%) out of 70 cancerous tissues contained DNA of EBV (28). However, Chang et al. reported that none of the 103 carcinoma tissues tested with the immunohistochemical technique was positive for $\mathrm{EBV}$ (30). By using in situ hybridization for EBER, Sunpaweravong et al. reported that none of the 104 esophageal cancer tissues were positive for EBV (31). In Iran, Yahyapour et al. showed that the frequency of EBV DNA was not significant between neoplastic and non-neoplastic tissue (32). While some studies have shown an association between EBV and esophageal carcinoma, others did not support these findings. This inconsistency might be, in part, due to the type of esophageal cancer, genetic background, environmental effects, sample size, as well as technical issues including the methods of detection (PCR, immunohistochemistry, or transcript analysis), type of sample (fresh or fixed), and differences in the extraction procedures.

There are 2 types of esophageal cancer including ESCC and EAC, which differ in the terms of geographical distribution, etiologies, and treatments. Although there is no published data with regards to the frequency of EBV in the EAC type of esophageal cancer, in our study the frequency of EBV was significantly higher in the EAC group than those with ESCC. The expression of EBERs in ESCC tissues has been previously confirmed by Wang et al. using in situ hybridization and PCR techniques (29). Moradi et al. have also reported that $6.5 \%$ of the samples taken from Iranian patients with ESCC in Mashhad contained the EBV genome (33). On the other hand, Anwar et al. reported that none of the 50 patients with ESCC was positive for EBER region using in situ hybridization assay in Pakistani patients (34). EBV DNA has not also been detected by typespecific PCR-based assay in the Greek population with ESCC (35). Further studies are warranted to decipher the potential role of EBV infection in the etiology of different types of esophageal carcinoma.

The frequency of CMV DNA was also found to be frequently higher in cancerous tissues than benign ones. Furthermore, the frequency of CMV DNA was significantly higher in patients with ESCC than those with EAC. In Japan, Megumi et al. reported a patient with esophageal cancer with CMV reactivation and significantly high CMV antigenemia (36). However, Chang et al. could not find the presence of CMV in 103 carcinoma tissues tested with immunohistochemistry technique (30). Similarly, Zhang et al. found no CMV DNA in either 70 tissue samples of esophageal cancer or normal mucosa sample (28).

Although the association of EBV with several types of cancer is well documented, this association has not been documented for CMV and only a few studies reported that CMV might be associated with some cancers in humans. In this regard, Silva et al. reported that CMV might be associated with hematologic malignancies including myeloid tumors (37). Moreover, CMV has been considered as a potential causative factor in the development of colon cancer (38). CMV genes and proteins have also been detected in different types of human cancers including prostate cancer, mucoepidermoid carcinoma of the salivary glands, glioblastomas, and medulloblastomas (20). In Iran, the CMV DNA genome has been detected in several types of cancers including colorectal (22), oral squamous cell carcinoma (23), and gastric cancers (24).

Inconsistent results regarding the frequency of $\mathrm{CMV}$ in esophageal cancer tissues in different studies may be due to several factors including sample size, sample type, detection methods, and different assays. Moreover, dietary, environmental factors, and genetic background may play a role in the etiology and pathogenesis of esophageal carcinomas (39), which need to be considered in this regard.

This finding increases the importance of EBV and CMV infection in human that increase the necessity of an effective vaccine for the prevention of these highly frequent viruses.

\subsection{Conclusions}

The data presented in this study indicate the possible role of EBV and CMV in different types of esophageal carcinoma. Higher frequency of EBV in EAC samples compared to ESCC samples may highlight the potential role of EBV in this type of esophageal cancer. A higher frequency of CMV in ESCC samples compared to those with EAC may also indicate the plausible role of CMV in the ESCC type of esophageal cancer. However, further comprehensive studies are needed to decipher the potential association between these viruses and different types of esophageal cancer. 


\section{Footnotes}

Authors' Contribution: It was not declared by the authors.

Conflict of Interests: informed consent was obtained before sample collection.

Ethical Approval: The study was approved by the Ethics Committee of the Shiraz University of Medical Sciences (IR.SUMS.REC.1395.51123)

Funding/Support: The present study was extracted from a thesis written by Ahmad Habibi, which was financially supported by a grant from Shiraz University of Medical Sciences (no: 94-11006).

\section{References}

1. Global Burden of Disease Cancer C, Fitzmaurice C, Allen C, Barber RM, Barregard L, Bhutta ZA, et al. Global, Regional, and National Cancer Incidence, Mortality, Years of Life Lost, Years Lived With Disability, and Disability-Adjusted Life-years for 32 Cancer Groups, 1990 to 2015: A Systematic Analysis for the Global Burden of Disease Study. JAMA Oncol. 2017;3(4):524-48. doi: 10.1001/jamaoncol.2016.5688. [PubMed: 27918777]. [PubMed Central: PMC6103527].

2. Gholipour M, Islami F, Roshandel G, Khoshnia M, Badakhshan A, Moradi A, et al. Esophageal Cancer in Golestan Province, Iran: A Review of Genetic Susceptibility and Environmental Risk Factors. Middle East J Dig Dis. 2016;8(4):249-66. doi: 10.15171/mejdd.2016.34. [PubMed: 27957288]. [PubMed Central: PMC5145292].

3. Castro C, Peleteiro B, Lunet N. Modifiable factors and esophageal cancer: a systematic review of published meta-analyses. J Gastroenterol. 2018;53(1):37-51. doi: 10.1007/s00535-017-1375-5. [PubMed: 28821981].

4. Sarvari J, Mojtahedi Z, Kuramitsu Y, Fattahi MR, Ghaderi A, Nakamura K, et al. Comparative Proteomics of Sera From HCC Patients With Different Origins. Hepat Mon. 2014;14(1). e13103. doi: 10.5812/hepatmon.13103. [PubMed: 24497876]. [PubMed Central: PMC3909643].

5. Shokouh MR, Safaei A, Moattari A, Sarvari J. Association of Human Papilloma Virus and Epstein-Barr Virus with Ovarian Cancer in Shiraz, Southwestern Iran. Iran J Pathol. 2020;15(4):292-8. doi: 10.30699/ijp.2020.119681.2306. [PubMed: 32944041]. [PubMed Central: PMC7477684].

6. Maronek M, Link R, Monteleone G, Gardlik R, Stolfi C. Viruses in Cancers of the Digestive System: Active Contributors or Idle Bystanders? Int J Mol Sci. 2020;21(21). doi: 10.3390/ijms21218133. [PubMed: 33143318]. [PubMed Central: PMC7663754].

7. Yahyapour Y, Shamsi-Shahrabadi M, Mahmoudi M, Siadati S, Shahryar SS, Shokri-Shirvani J, et al. Evaluation of human papilloma virus infection in patients with esophageal squamous cell carcinoma from the Caspian Sea area, north of Iran. Asian Pac J Cancer Prev. 2012;13(4):12616. doi: 10.7314/apjcp.2012.13.4.1261. [PubMed: 22799315].

8. Xu W, Liu Z, Bao Q, Qian Z. Viruses, Other Pathogenic Microorganisms and Esophageal Cancer. Gastrointest Tumors. 2015;2(1):213. doi: 10.1159/000380897. [PubMed: 26674173]. [PubMed Central: PMC4668794].

9. Genitsch V, Novotny A, Seiler CA, Kroll D, Walch A, Langer R. Epsteinbarr virus in gastro-esophageal adenocarcinomas - single center experiences in the context of current literature. Front Oncol. 2015;5:73. doi: 10.3389/fonc.2015.00073. [PubMed: 25859432]. [PubMed Central: PMC4374449].

10. Sarvari J, Mahmoudvand S, Pirbonyeh N, Safaei A, Hosseini SY. The Very Low Frequency of Epstein-Barr JC and BK Viruses DNA in Colorectal Cancer Tissues in Shiraz, Southwest Iran. Pol J Microbiol. 2018;67(1):739. doi: 10.5604/01.3001.0011.6146. [PubMed: 30015427].
11. Elgui de Oliveira D, Muller-Coan BG, Pagano JS. Viral Carcinogenesis Beyond Malignant Transformation: EBV in the Progression of Human Cancers. Trends Microbiol. 2016;24(8):649-64. doi: 10.1016/j.tim.2016.03.008. [PubMed: 27068530]. [PubMed Central: PMC5489061].

12. Zuo L, Yue W, Du S, Xin S, Zhang J, Liu L, et al. An update: Epstein-Barr virus and immune evasion via microRNA regulation. Virol Sin. 2017;32(3):175-87. doi: 10.1007/s12250-017-3996-5. [PubMed: 28669004]. [PubMed Central: PMC6702289].

13. Kang D, Skalsky RL, Cullen BR. EBV BART MicroRNAs Target Multiple Pro-apoptotic Cellular Genes to Promote Epithelial Cell Survival. PLoS Pathog. 2015;11(6). e1004979. doi: 10.1371/journal.ppat.1004979. [PubMed: 26070070]. [PubMed Central: PMC4466530].

14. Agholi M, Safaei A, Ramzi M, Hatam GR, Sarvari J. A survey of the frequency of cytomegalovirus-associated diarrhea in immunocompromised patients using a non-invasive method. Iran J Microbiol. 2018;10(2):143-50. [PubMed: 29997755]. [PubMed Central: PMC6039454].

15. Rahbar A. Promotion of Tumorigenesis and Clinical Implications of Viral Infection in Breast Cancer. J Carcinog Mutagen. 2015;6(2). doi: 10.4172/2157-2518.1000217.

16. Harkins LE, Matlaf LA, Soroceanu L, Klemm K, Britt WJ, Wang W, et al. Detection of human cytomegalovirus in normal and neoplastic breast epithelium. Herpesviridae. 2010;1(1):8. doi: 10.1186/2042-4280-18. [PubMed: 21429243]. [PubMed Central: PMC3063230].

17. Song YJ, Stinski MF. Inhibition of cell division by the human cytomegalovirus IE86 protein: role of the p53 pathway or cyclindependent kinase 1/cyclin B1. J Virol. 2005;79(4):2597-603. doi: 10.1128/JVI.79.4.2597-2603.2005. [PubMed: 15681459]. [PubMed Central: PMC546562].

18. Kwon Y, Kim MN, Young Choi E, Heon Kim J, Hwang ES, Cha CY. Inhibition of p53 transcriptional activity by human cytomegalovirus UL44. Microbiol Immunol. 2012;56(5):324-31. doi: 10.1111/j.13480421.2012.00446.x. [PubMed: 22376288].

19. Dziurzynski K, Chang SM, Heimberger AB, Kalejta RF, McGregor Dallas SR, Smit M, et al. Consensus on the role of human cytomegalovirus in glioblastoma. Neuro Oncol. 2012;14(3):246-55. doi: 10.1093/neuonc/nor227. [PubMed: 22319219]. [PubMed Central: PMC3280809].

20. El-Shinawi M, Mohamed HT, El-Ghonaimy EA, Tantawy M, Younis A, Schneider RJ, et al. Human cytomegalovirus infection enhances NFkappaB/p65 signaling in inflammatory breast cancer patients. PLoS One. 2013;8(2). e55755. doi: 10.1371/journal.pone.0055755. [PubMed: 23418456]. [PubMed Central: PMC3572094].

21. Richardson AK, Currie MJ, Robinson BA, Morrin H, Phung Y, Pearson $\mathrm{JF}$, et al. Cytomegalovirus and Epstein-Barr virus in breast cancer. PLoS One. 2015;10(2). e0118989. doi: 10.1371/journal.pone.0118989. [PubMed: 25723522]. [PubMed Central: PMC4344231].

22. Tafvizi F, Fard ZT. Detection of human cytomegalovirus in patients with colorectal cancer by nested-PCR. Asian Pac J Cancer Prev. 2014;15(3):1453-7. doi: 10.7314/apjcp.2014.15.3.1453. [PubMed: 24606482].

23. Delavarian Z, Pakfetrat A, Falaki F, Pazouki M, Pazouki N. The Role of Viruses in Oral Squamous Cell Carcinoma in Young Patients in Khorasan (Northeast of Iran). J Appl Sci. 2010;10(11):981-5. doi: 10.3923/jas.2010.981.985.

24. Leila Z, Arabzadeh SA, Afshar RM, Afshar AA, Mollaei HR. Detection of Epstein-Barr Virus and Cytomegalovirus in Gastric Cancers in Kerman, Iran. Asian Pac J Cancer Prev. 2016;17(5):2423-8. [PubMed: 27268608].

25. Ahangar-Oskouee M, Shahmahmoodi S, Jalilvand S, Mahmoodi M, Ziaee AA, Esmaeili HA, et al. No detection of 'high-risk' human papillomaviruses in a group of Iranian women with breast cancer. Asian Pac J Cancer Prev. 2014;15(9):4061-5. doi: 10.7314/apjcp.2014.15.9.4061. [PubMed: 24935597]. 
26. Khabaz MN. Association of Epstein-Barr virus infection and breast carcinoma. Arch Med Sci. 2013;9(4):745-51. doi: 10.5114/aoms.2013.37274. [PubMed: 24049539]. [PubMed Central: PMC3776191].

27. Kim JH, Collins-McMillen D, Buehler JC, Goodrum FD, Yurochko AD, Frueh K. Human Cytomegalovirus Requires Epidermal Growth Factor Receptor Signaling To Enter and Initiate the Early Steps in the Establishment of Latency in CD34 + Human Progenitor Cells. J Virol. 2017;91(5). doi: 10.1128/jvi.01206-16.

28. Zhang DH, Zhang QY, Hong CQ, Chen JY, Shen ZY, Zhu Y. Prevalence and association of human papillomavirus 16, Epstein-Barr virus, herpes simplex virus-1 and cytomegalovirus infection with human esophageal carcinoma: a case-control study. Oncol Rep. 2011;25(6):17318. doi: 10.3892/or.2011.1234. [PubMed: 21455581].

29. Wang LS, Chow KC, Wu YC, Li WY, Huang MH. Detection of EpsteinBarr virus in esophageal squamous cell carcinoma in Taiwan. Am J Gastroenterol. 1999;94(10):2834-9. doi: 10.1111/j.1572-0241.1999.01425.x. [PubMed: 10520830].

30. Chang F, Syrjanen S, Shen Q, Cintorino M, Santopietro R, Tosi P, et al. Evaluation of HPV, CMV, HSV and EBV in esophageal squamous cell carcinomas from a high-incidence area of China. Anticancer Res. 2000;20(5C):3935-40. [PubMed: 11268480].

31. Sunpaweravong S, Mitarnun W, Puttawibul P. Absence of EpsteinBarr virus in esophageal squamous cell carcinoma. Dis Esophagus. 2005;18(6):398-9. doi: 10.1111/j.1442-2050.2005.00522.x. [PubMed: 16336611].

32. Yahyapour Y, Rahmani R, Alipour M, Alizadeh A, Khademian A, Sadeghi F. Prevalence and association of human papillomavirus, Epstein-Barr virus and Merkel Cell polyomavirus with neoplastic esophageal lesions in northern Iran. Caspian I Intern Med.
2018;9(4):353-60. doi: 10.22088/cjim.9.4.353. [PubMed: 30510650]. [PubMed Central: PMC6230459].

33. Moradi A, Ghasemi F, Anvari K, Simab SA, Hassanian SM, Ebrahimi S, et al. Association of Epstein-Barr virus with Esophageal squamous cell carcinoma. Middle East J Cancer. 2018;9(2):91-7.

34. Anwar M, Koriyama C, Naveed IA, Hamid S, Ahmad M, Itoh T, et al. Epstein-barr virus detection in tumors of upper gastrointestinal tract. An in situ hybridization study in Pakistan.J Exp Clin Cancer Res. 2005;24(3):379-85. [PubMed: 16270524].

35. Lyronis ID, Baritaki S, Bizakis I, Tsardi M, Spandidos DA. Evaluation of the prevalence of human papillomavirus and Epstein-Barr virus in esophageal squamous cell carcinomas. Int J Biol Markers. 2005;20(1):510. doi: 10.5301/jbm.2008.4549. [PubMed: 15832767].

36. Megumi K, Okumura H, Shimonosono M, Ijichi T, Uchikado Y, Omoto I, et al. A Case of Esophageal Cancer in a Patient with CMV Reactivation after Neoadjuvant Chemoradiation Therapy. Gan To Kagaku Ryoho. 2015;42(10):1307-9.

37. de Melo Silva J, Pinheiro-Silva R, Dhyani A, Pontes GS. Cytomegalovirus and Epstein-Barr Infections: Prevalence and Impact on Patients with Hematological Diseases. Biomed Res Int. 2020;2020:1627824. doi: 10.1155/2020/1627824. [PubMed: 33163531]. [PubMed Central: PMC7605947].

38. Antonic V, Stojadinovic A, Kester KE, Weina PJ, Brucher BL, Protic $M$, et al. Significance of infectious agents in colorectal cancer development. J Cancer. 2013;4(3):227-40. doi: 10.7150/jca.5835. [PubMed: 23459622]. [PubMed Central: PMC3584836].

39. Hortal AM, Vermeulen JF, Van Hecke W, Bovenschen N. Oncogenic role of cytomegalovirus in medulloblastoma? Cancer Lett. 2017;408:55-9. doi:10.1016/j.canlet.2017.08.024. [PubMed: 28844716]. 